\title{
Memprediksi Jumlah Siswa Baru Menggunakan Metode Backpropagation (STUDI KASUS: SMK HARAPAN BANGSA KUALA)
}

\author{
Kris Jayanti ${ }^{1}$, Katen Lumbanbatu ${ }^{2}$, Suci Ramadani ${ }^{3}$ \\ STMIK Kaputama Binjai, Jl. Veteran No. 4A-9A, Binjai, Sumatera Utara, Indonesia \\ krisj8106@gmail.com ${ }^{1 *}$, katenlumbanbatu@gmail.com ${ }^{2}$, suciramadani@gmail.com ${ }^{3}$
}

\begin{abstract}
Abstrak. Jaringan Syaraf Tiruan (JST) dan data time series dapat digunakan untuk metode peramalan dengan baik. Jaringan Syaraf Tiruan adalah suatu metode yang prinsip kerjanya diadaptasi dari model matematika pada manusia atau syaraf biologi. Jaringan syaraf dikarakteristikkan oleh; (1) pola koneksi diantara neuron (disebut arsitektur), (2) menentukan bobot dari koneksi (disebut training atau learning), dan (3) fungsi aktifasi. Tujuan penelitian adalah mendapatkan arsitektur jaringan syaraf tiruan yang terbaik, membandingkan dua metode Jaringan Syaraf Tiruan Backpropogation dengan metode Jaringan Syaraf Tiruan Fungsi Basis Radial $(R B F)$. Penelitian ini merupakan penelitian dengan menggunakan data yang sebenarnya (true experimental). Penelitian ini dilaksanakan di SMK Harapan Bangsa Kuala, yang diperoleh dari tahun 2015 sampai dengan 2019. Hasil penelitian menunjukkan adanya untuk satu iterasi menggunakan metode backpropagation hasilnya 0,378197657dengan jumlah kuadrat error 0,143033468, maka hasil yang dicapai belum sesuai dengan target.
\end{abstract}

Kata Kunci : Backpropagation, Prediksijumlah siswa baru, Jaringan syaraf tiruan.

Abstract. Artificial Neural Network (ANN) and time series data can be used for forecasting methods well. Artificial Neural Network is a method whose working principle is adapted from a mathematical model in humans or biological nerves. Neural networks are characterized by; (1) the pattern of connections between neurons (called architecture), (2) determining the weight of the connection (called training or learning), and (3) the activation function. The research objective was to obtain the best artificial neural network architecture, comparing the two methods of Backpropogation Neural Networks with the Radial Base Function Artificial Neural Network (RBF) method. This research is a research using real data (true experimental). This research was conducted at SMK Harapan Bangsa Kuala, which was obtained from 2015 to 2019. The results showed that for one iteration using the backpropagation method the result was 0,378197657 with a squared error 0.143033468 , then the results achieved were not in accordance with the target.

Keyword: Backpropagation, Prediction of the number of new students, Artificial Neural Networks.

\section{PENDAHULUAN}

Penyeleksian atau penerimaan siswa baru adalah suatu hal yang perlu ditentukan secara cepat dan tepat. Dalam hal penentuan jumlah calon siswa baru diperlukan beberapa pertimbangan yang cukup banyak dan rumit, jumlah calon siswa yang sering berubah setiap tahunnya[1]. Untuk memperoleh jumlah calon siswa baru, untuk penyeleksian jumlah calon siswa baru yang standart harus menetap kan kriteria-kriteria yang sesuai dan juga harus dipersiapkan dengan semaksimal mungkin. Sekolah yang jumlah pendaftarannya tiap tahun meningkat dilihat dari tahun-tahun sebelumnya, hal ini menyebabkan panitia penerimaan calon siswa baru tidak dapat mengelola semuanya dengan baik dan merasa kerepotan menangani hal tersebut[2].

Selama ini permasalahan penerimaan calon siswa baru dengan cara konvensional sangatlah sulit apa lagi hanya dengan melihat nilai akhir atau UN saja, karena dengan nilai yang tinggi belum tentu bisa menjamin bahwa calon siswa tersebut dapat diterima atau tidak[3]. Sistem seleksi konvensional merupakan tahap awal pada saat seleksi penerimaan calon siswa baru, dengan dibantu komputer dampen dekatan jaringan syaraf tiruan diharapkan dapat membantu seleksi masuk calon mahsiswa baru. Dengan jaringan syaraf tiruan komputer difungsikan sebagai alat bantu yang dapat memprediksi calon siswa baru tersebut[4]. 
Penerapan metode jaringan syaraf tiruan backpropagation telah banyak dilakukan oleh para peneliti sebelumnya diantara penelitian tersebut yaitu sarjon defit yang berjudul "(2019) implementasi metode backpropaation untuk memprediksi tingkat kelulusan uji kompetensi siswa".

\section{METODOLOGI PENELITIAN}

Metode penelitian dilakukan untuk mencari sesuatu secara sistematis dengan menggunakan metode ilmiah serta sumber yang berlaku. Dalam proses penelitian ini ditunjukan ke semua pihak, terutama kepada pihak yang bertanggung jawab mengenai penerimaan siswa baru, sehingga dapat memberikan hasil yang diharapkan. Hasil dari konseptualisasi ini akan dituangkan menjadi suatu metode penelitian yang lengkap dengan pola studi literature, pengumpulan data yang diperlukan untuk menganalisis sistem prediksi yang akan dibuat yaitu untuk memprediksi jumlah siswa baru dengan menggunakan algoritma Backpropagation[5], [6].

\subsection{Pengertian Backpropogation}

Backpropogation adalah algoritma pembelajaran yang terawasi dan biasanya digunakan oleh perpectron dengan banyak lapisan untuk mengubah bobot-bobot yang terhubung dengan neuronneuron yang ada pada lapisan tersembunyinya. Algoritma backpropogation menggunakan error output untuk mengubah nilai bobot-bobotnya dalam arah mundur (backward) [7]. Untuk mendapatkan error ini, tahap perambatan maju (forward propogation) harus dikerjakan terlebih dahulu. Pada saat perambatan maj, neuron-neuron diaktifkan dengan menggunakan fungsi aktivasi yang dapat dideferensiasikan, seperti sigmoid[8].

\subsection{Pengertian Prediksi}

Prediksi adalah sama dengan ramalan atau perkiraan. Menurut kamus besar bahasa indonesia. Prediksi adalah hasil dari kegiatan memprediksi atau meramal atau memperkirakan [9]. Prediksi atau ramalan adalah proses untuk memperkirakan beberapa kebutuhan dimasa yang akan datang yang meliputi kebutuhan dalam ukuran kuntitas, kualitas, waktu dan lokasi yang dibutuhkan dalam rangka yang dibutuhkan dalam rangka memenuhi permintaan barang atau jasa[10].

\section{HASIL DAN PEMBAHASAN}

Seluruh data variabel yang terkumpul dipisahkan menjadi dua bagian, yaitu masukan dan keluaran. Data masukan berfungsi sebagai proses pelatihan dan pengujian, sedangkan data keluaran berfungsi sebagai data target pencapaian proses. Adapun data yang digunakan berasal dari jumlah siswa baru selama lima tahun, yaitu tahun 2015, 2016, 2017, 2018 dan 2019 yang dapat dilihat pada tabel di bawah ini.

\begin{tabular}{|c|c|c|c|c|c|}
\hline \multirow{2}{*}{ 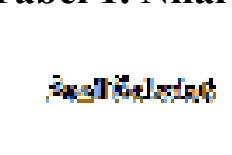 } & \multicolumn{2}{|c|}{ 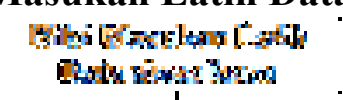 } & \multirow{2}{*}{ 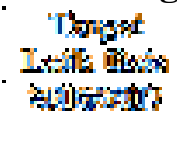 } & \multicolumn{2}{|c|}{ 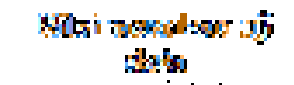 } \\
\hline & istaratex & 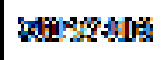 & & צropane & $\frac{29}{59}$ \\
\hline 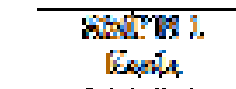 & सए & यद्ध & 34 & \& & m \\
\hline 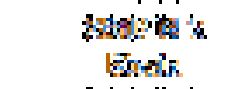 & $x$ & $\$$ & ss & $5 s$ & $3 n$ \\
\hline 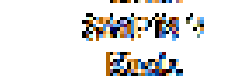 & sa & $\mathrm{ms}$ & צㄴ & ms & $\$$ \\
\hline 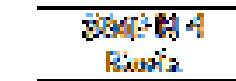 & Ril & is: & का & 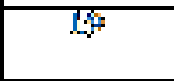 & 2 \\
\hline DASF & 89 & $F$ & 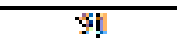 & 3 & \$ss. \\
\hline 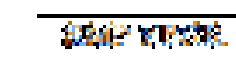 & $D$ & 8 & 8 & * & $\frac{1}{5}$ \\
\hline
\end{tabular}


Keterangan:

$(0.8)=$ Ketetapan

(a) = Nilai data terendah (data terendah dari setiap input)

(x) = Nilai data ke $-\mathrm{n}$

(b) = Nilai data tertinggi (data tertinggi dari setiap input)

Berikut ini tabel hasil transformasi dari nilai masukan data latih dan target

Tabel 2. Proses Perhitungan tahun 2014/2015

\begin{tabular}{|ll|ll|}
\hline$\frac{0,8^{*}(40-0)}{(50-0)}$ & $+0,1=0,74$ & $\frac{0,8^{*}(12-0)}{(0-)}+0,1=0,1$ \\
\hline$\frac{0,8^{*}(25-0)}{(50-0)}+0,1=0,05$ & $\frac{0,8^{*}(4-0)}{(50-0)}$ & $+0,1=0,1$ \\
\hline$\frac{0,8^{*}(23-0)}{(50-0)}$ & $+0,1=0,1$ & $\frac{0,8^{*}(4-0)}{(50-0)}$ & $+0,1=0,1$ \\
\hline$\frac{0,8^{*}(11-0)}{(108-7)}$ & $+0,1=0,1$ & $\frac{0,8^{*}(3-0)}{(50-0)}$ & $+0,1=0,1$ \\
\hline$\frac{0,8^{*}(13-0)}{(50-0)}$ & $+0,1=0,1$ & $\frac{0,8^{*}(4-0)}{(50-0)}$ & $+0,1=0,1$ \\
\hline$\frac{0,8^{*}(0-0)}{(50-7)}$ & $+0,1=0,1$ & $\frac{0,8 *(0-0)}{(5(-0)}+0,1=0,1$ \\
\hline
\end{tabular}

\subsection{Contoh Perhitungan}

Proses secara manual menggunakan data siswa baru, selama 5 tahun pada tahun 2015, 2016, 2017, 2018 dan 2019.

\begin{tabular}{|c|c|c|c|c|c|}
\hline \multirow{2}{*}{ Whas } & \multicolumn{2}{|c|}{ 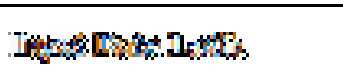 } & \multirow{2}{*}{ 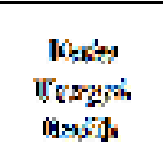 } & \multirow{2}{*}{ 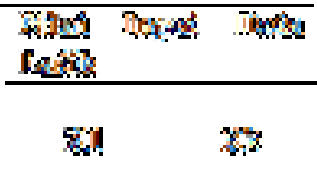 } & \multirow{2}{*}{$\begin{array}{l}\text { (xind } \\
\text { Texpos: } \\
\text { itsos: }\end{array}$} \\
\hline & खू & ngen & & & \\
\hline $2 \times x: 1$ & satemavis & Makesos & trilstantos & 垁 & 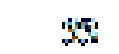 \\
\hline
\end{tabular}

Adapun tabel hasil transformasi sebagai berikut :

\begin{tabular}{|c|c|c|c|c|c|c|}
\hline \multirow{2}{*}{ Pola } & \multicolumn{2}{|c|}{ Input Data Latih } & \multirow{2}{*}{$\begin{array}{c}\text { Data } \\
\text { Target } \\
\end{array}$} & \multicolumn{2}{|c|}{$\begin{array}{c}\text { Nilai Input Data } \\
\text { Latih }\end{array}$} & $\begin{array}{c}\text { Nilai } \\
\text { Target } \\
\text { Latih }\end{array}$ \\
\cline { 2 - 3 } & $\mathrm{X} 1$ & $\mathrm{X} 2$ & Latih & $\mathrm{X} 1$ & $\mathrm{X} 2$ & \\
\hline Pola-1 & $2014 / 2015$ & $2015 / 2016$ & $2016 / 2017$ & 0,74 & 0,6032 & 0,628 \\
\hline
\end{tabular}

Arsitektur jaringan syaraf tiruan menggunakan algoritma backpropagation terdiri dari: 


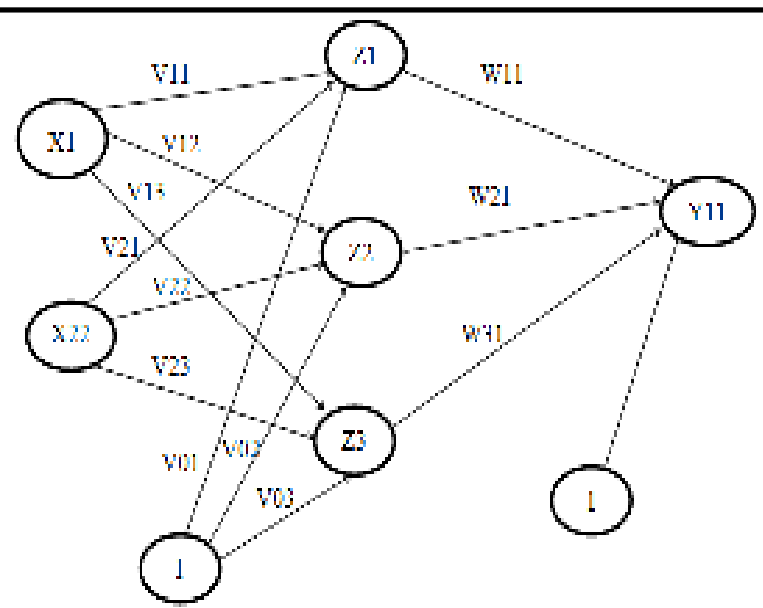

Gambar 1. Arsitektur Backpropagation

1. Lapisan masukan (Xi) terdiri dari 2 neuron.

2. Lapisan tersembunyi ( $\mathrm{Zi}$ ) terdiri dari 3 neuron.

3. Lapisan keluaran (Yi) terdiri dari 1 neuron.

4. Learning rate $(\alpha)=0,2$

5. Target error $=0,01$

6. Konstanta Bias.

7. Arsitektur JST

Dari Arsitektur jaringan syraf tiruan diatas, jaringan terdiri dari atas unit (Neuron) pada lapisan input yaitu, X1 dan X2 yang mana X1 dan X2 merupakan data jumlah siswa, 2 unit (neuron) lapisan hiden dengan jumlah sel yang sudah ditetapkan secara random yaitu, Z1 dan Z2 dan Z3, 1 unit (neuron) dengan jumlah lapisan output yaitu Y1. Selain itu terdapat juga 1 unit (neuron)bias pada lapisan input yaitu V0 dan 1 unit (neuron)bias pada lapisan output W11

Berikut ini merrupakan perhitungan pelatihan menggunakan algoritmabackpropagation.

1. Learning rate $(\alpha)=0,2$

2. Target error $=0,01$

3. Maksimum epoch $=10000$

4. Target $=0,178$

\subsection{Pembahasan Antar Muka}

Dalam pembahasan antar muka ini akan dijelaskan mengenai hasil perancangan pemrograman yang menggunakan GUI matlab. Adapun rancangan yang dibuat meliputi menu untuk halaman utama, login, peelatihan dan pengujian, Menu analisa, menu grafik, info dan help. jaringan syaraf tiruan untuk memprediksi jumlah siswa baru seperti di bawah ini.

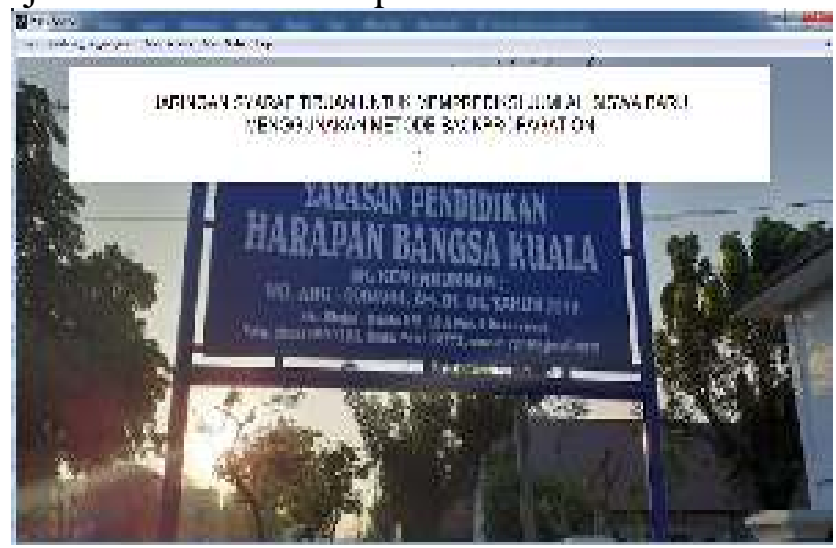

Gambar 2. Halaman Utama 
Pada menu pelatihan dana pengujian berisi tentang proses penginputan data yang akan dilatih dan diuji menggunakan metode backpropagation. Dengan cara menginputkan data latih dan target latih, kemudian memilih fungsi aktivasi dan dilanjutkan pada proses penginputan maksimum epoch, targeterror dan learningrate kemudian klik tombol proses pelatihan. Langkah selanjutnya proses penginputan data uji setelah selesai klik tombol proses pengujian dan pelatihan maka akan mendapatkan hasil prediksi data seperti di bawah ini.

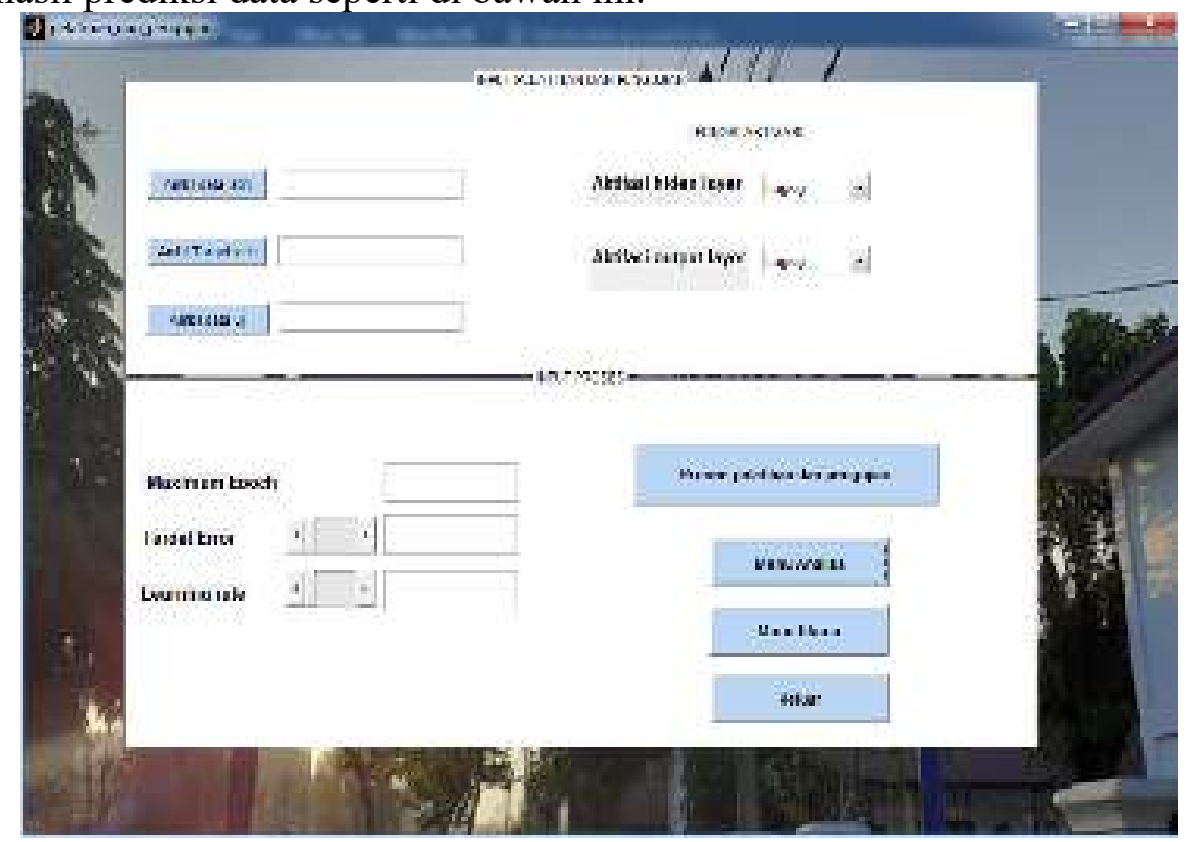

Gambar 3. Menu Pengujian dan peelatihan

\subsection{Analisa Data}

Menu analisa data ini dirancang untuk menampilkan hasil perbandingan antara data lama dengan data prediksi. Pilih button sesuai dengan data yang sudah dilatih pada menu JST_Backpro untuk menampilkan menu hasilnya. Adapun tampilan menu Analisa Data prediksi jumlah Siswa baru menggunakan metode backpropagation. Data akan dilatih dengan pengaruh model algoritma jaringan syaraf tiruan. Jumlah data input, jumlah lapisan tersembunyi dan output jumlah siswa baru yang digunakan untuk menghasilkan iterasi tercepat dengan nilai-nilai lapisan tersembunyi yang berubahubah.

Hasil pelatihan dilakukan melalui dua tahap, yaitu tahap pelatihan data yang dilatih, dan tahap pengujian data yang baru, yang belum pernah dilatih yang terdiri dari 6 data yaitu jumlah siswa aru selama 2 tahun yaitu tahun 2015 dan 2016. Setelah itu, jaringan akan diuji dengan 6 data baru yaitu jumulah siswa baru 2017. Hal tersebut berfungsi untuk menguji seberapa besar jaringan syaraf tiruan dapat mengenali data yang baru.

Data inputan diambil dari data jumalah siswa baruselama 5 tahun yaitu tahun 2015, 2016, 2017, 2018, dan 2019 yang akan dilatih pada jaringan sebanyak6 data latih, 6 data target latih dan 6 data sebagai data target. Data tersebut akan digunakan untuk menguji keakuratan sistem dalam mengenali masukan data yang lain. Seluruh data variabel akan dipisahkan menjadi dua bagian, yaitu data masukan dan data keluaran. Data masukan berfungsi sebagai proses pelatihan dan pengujian. Sedangkan data keluaran sebagai data target pencapaian proses.

Menu analisa data ini dirancang untuk menampilkan hasil perbandingan antara data lama dengan data prediksi. Pilih button sesuai dengan data yang sudah dilatih pada menu JST_Backpro untuk menampilkan menu hasilnya. Adapun tampilan menu Analisa Data prediksi jumlah Siswa arumenggunakan metode backpropagation yaitu seperti pada Gambar di bawah ini 


\begin{tabular}{|c|c|c|c|c|c|}
\hline & ASAL SEKOLSH & $\pi / \alpha$ ) & T/K X1A:2019 & Th, 201andols & PREDXST T/A Za19/20100 \\
\hline 1 & SAPH: KüL & 3 & $<0$ & 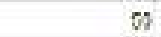 & 13.5874 \\
\hline 2. & Sup N 2 Kuik & $\pi$ & 27 & ग & 18.626 \\
\hline 3 & SuPN3Kuati & 2 & 31 & 29 & 126213 \\
\hline. & SUP N 4 Kusta & 21 & 19 & 22 & 186220 \\
\hline 5 & SHPYRTY & St & s: & 31 & 186234 \\
\hline 6 & GUPYP:R & 3 & a & a & 2.1929 \\
\hline 7 & SUP N Y Satesal & $i$ & 14 & is & 15.2526 \\
\hline 8 & AVF 11 Salspis & s & s & a & $10 \times 4.4$ \\
\hline 9 & SAP M 2 Sulepan & 19 & 3 & 11 & 17:TMP \\
\hline 10 & ITS Mirui abn. & 10 & 0 & 5 & $18500=$ \\
\hline II & SUP M S Scisicui & 0 & 2 & j & 3.9047 \\
\hline 12 & 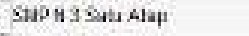 & 2 & a & 7 & 56035 \\
\hline 13 & SAP W D Hepa! & 1 & 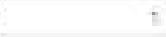 & 1 & 4.1521 \\
\hline 11 & SHP Ponpes Almethent & 3 & 4 & 4 & 5.5020 \\
\hline is & IITS kign harth & 3 & 4 & 5 & 5.0020 \\
\hline 16 & GAP N V Gnevare & 1 & 3 & 2 & $5.72 \%$ \\
\hline if & GAP Gwsksys ask' & * & 3 & $s$ & $527 i 4$ \\
\hline Is: & slp Swacspy Felape & 2 & $z$ & $z$ & 1775 \\
\hline 19 & SAP Hin iabn Kanscipte & 2 & 2 & 2 & 4.7235 \\
\hline 20 & SAPM9 Batuลi & 4 & J & 4 & 5.1209 \\
\hline 21 & SAPM 5 Swiburn & 1 & 4 & 5 & 6.5121 \\
\hline 12 & SAP M A Eargathe & 4 & 2 & 4 & 4.6835 \\
\hline 3 & 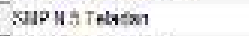 & s & 6 & 7 & 7.2495 \\
\hline 21 & 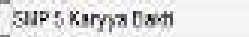 & 3 & 3 & + & 5.2774 \\
\hline is & GNP 4 Dargstsu & 4 & s & $\theta$ & 6.4520 \\
\hline 26 & GIP N S Soro Warlst & 4 & 2 & $=$ & 4 wasts \\
\hline 25 & SUPH - SAI 3ugs & 2 & . & I & 3es44. \\
\hline
\end{tabular}

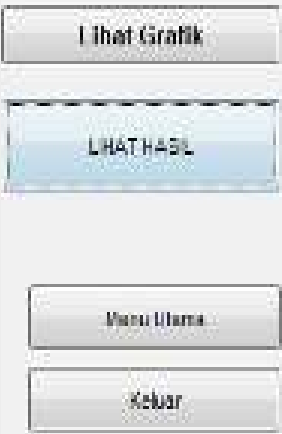

\section{Gambar 4. Menu Analisa Data Prediksi Jumlah Siswa}

Menu grafik data ini berisi tentang rata-rata data, baik rata-rata data Jumlah siswa lama maupun rata-rata data hasil prediksi. Pilih edit teks sesuai dengan data yang sudah dilatih pada menu Analisa untuk menampilkan hasilnya. Adapun tampilan menu grafik data untuk memprediksi jumlah Siswa Baru menggunakan metode backpropagation yaitu seperti pada Gambar di bawah ini

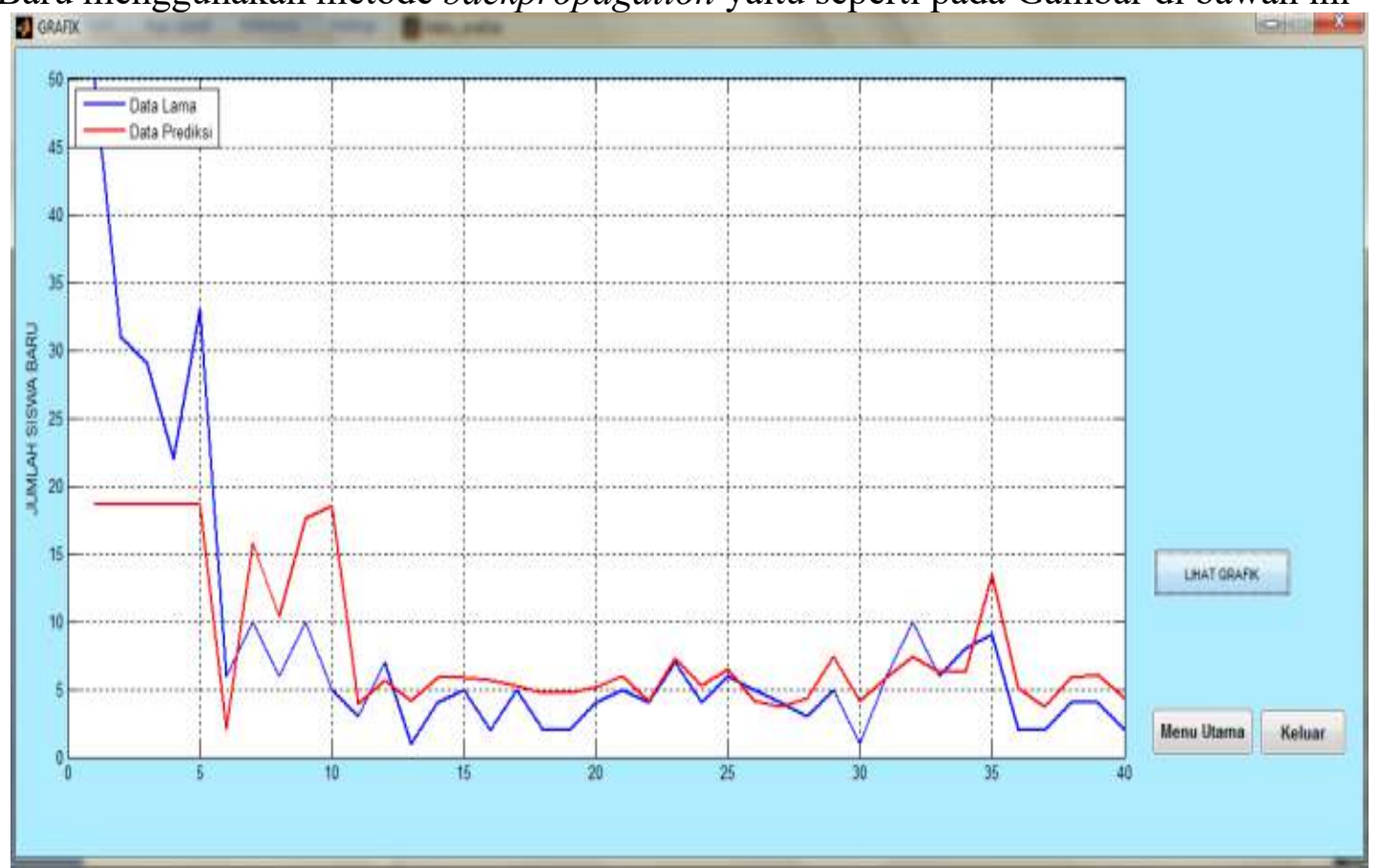

Gambar 5. Menu Grafik Data Prediksi Jumlah Siawa Baru 


\section{KESIMPULAN}

Berdasarkan hasil penelitian yang telah dilakukan menghasilkan sebuah perangkat lunak (software) yang dapat memprediksi jumlah Siswa baru dengan menggunakan jaringan syaraf tiruan backpropagation. Selama proses perancangan dan implementasi program aplikasi pengenalan pola dapat diambil kesimpulan sebagai berikut:

1. Menganalisa data-data jumlah siswa baru dapat dikenali oleh sistem jaringan syaraf tiruan dengan metode backpropagation, hasil dari pengujian ada yang mengalami peningkatan dan penurunan.

2. Hasil Jumlah siswa bbaru setelah melakukan proses pelatihan dan pengujian maka hasil prediksi produksi jumlah siswa aru mengalami peningkatan dengan rata-rata hasil prediksi 42.0786 Untuk jumlah siswa baru mengalami peningkatan

3. Dengan adanya aplikasi ini, data hasil pelatihan dan pengujian yang telah diperoleh dapat diketahui informasi mengenai jumlah prediksi Jumlah siswa baru Berdasarkan grafik

\section{DAFTAR PUSTAKA}

[1] R. Rachman and A. Mukminin, "Penerapan Metode Certainty Factor Pada Sistem Pakar Penentuan Minat dan Bakat Siswa SD," Khazanah Informatika: Jurnal Ilmu Komputer dan Informatika, 2018, doi: 10.23917/khif.v4i2.6828.

[2] E. N. Wahyudi, "Teknik Klasifikasi untuk Melihat Kecenderungan Calon Mahasiswa Baru dalam Memilih Jenjang Pendidikan Program Studi di Perguruan Tinggi," Teknologi Informasi DINAMIK, vol. 18, no. 1, pp. 55-64, 2013.

[3] J. Purnama, "SISTEM PENDUKUNG KEPUTUSAN SELEKSI PENERIMAAN SISWA BARU MENGGUNAKAN METODE SIMPLE ADDITIVE WEIGHTING (SAW) (Studi Kasus : SMA Negeri 01 Kalirejo).” [Online]. Available: www.stmikpringsewu.ac.id

[4] J. J. Siang, "Jaringan Syaraf Tiruan \& Pemrogramannya Menggunakan Matlab,” 2009, Accessed: May 29, 2021. [Online]. Available:

//fia.ub.ac.id/katalog/index.php?p=show_detail\&id=7824\&keywords=

[5] S. Arikunto, "Metodelogi penelitian," Yogyakarta: Bina Aksara, 2006.

[6] Sugiyono, Metode Penelitian Kuantitatif, Kualitatif dan R\&D. Bandung: PT Alfabet, 2016.

[7] M. Agustin and T. Prahasto, "Penggunaan Jaringan Syaraf Tiruan Backpropagation Untuk Seleksi Penerimaan Mahasiswa Baru Pada Jurusan Teknik Komputer Di Politeknik Negeri Sriwijaya," JURNAL SISTEM INFORMASI BISNIS, vol. 2, no. 2, pp. 089-097, Jun. 2012, doi: 10.21456/vol2iss2pp089-097.

[8] I. Taufik and A. Sitio, "IMPLEMENTASI JARINGAN SYARAF TIRUAN UNTUK PENGELOMPOKKAN MINAT KOMPETENSI MAHASISWA STMIK PELITA NUSANTARA MEDAN," Jurnal Mantik Penusa, vol. 2, no. 2, pp. 80-83, 2018.

[9] B. S. Koentjoro, I. S. Sitanggang, and A. K. Makarim, "Model Simulasi dan Visualisasi Prediksi Potensi Hasil dan Produksi Kedelai di Jawa Timur," Jurnal Penelitian Pertanian Tanaman Pangan, vol. 34, no. 3, p. 195, 2016, doi: 10.21082/jpptp.v34n3.2015.p195-201.

[10] R. S. Wahono, "Penerapan Algoritma Genetika untuk Optimasi Parameter pada Support Vector Machine untuk Meningkatkan Prediksi Pemasaran Langsung," Journal of Intelligent Systems, vol. 1, no. 2, pp. 115-119, 2015. 